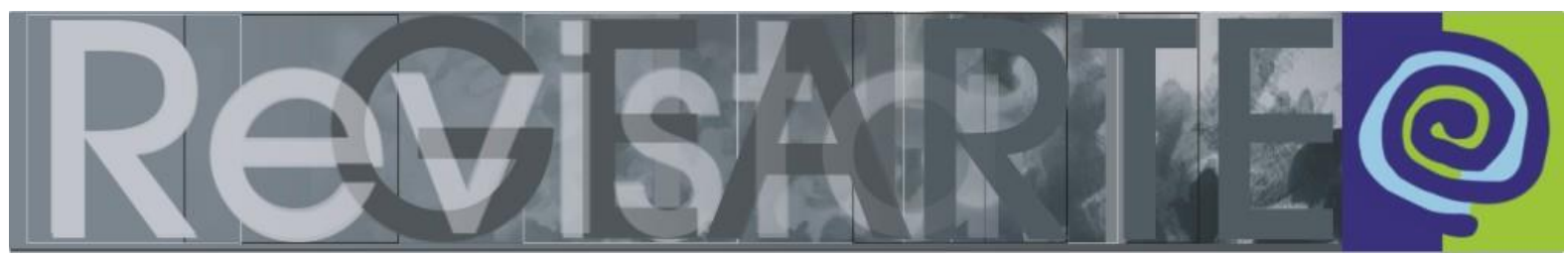

e-ISSN 2357-9854

\title{
Abordagem Triangular: ziguezagueando entre um ideário e uma ação reconstrutora para o ensino de artes
}

\author{
Sidiney Peterson (Universidade Estadual Paulista \\ Júlio de Mesquita — UNESP, São Paulo/SP, Brasil) \\ Rejane Galvão Coutinho (Universidade Estadual Paulista \\ Júlio de Mesquita — UNESP, São Paulo/SP, Brasil)
}

\begin{abstract}
RESUMO - Abordagem Triangular: ziguezagueando entre um ideário e uma ação reconstrutora para o ensino de artes - A arte-educadora Ana Mae Barbosa organizou e publicou junto com Fernanda Pereira da Cunha o livro Abordagem Triangular no ensino das artes e culturas visuais (CORTEZ, 2010), no qual fez um balanço dos vinte anos de experiências com a Abordagem Triangular no ensino de artes no Brasil. O livro faz um apanhado de algumas interpretações e revela facetas dessa múltipla Abordagem que vem desde a década de 1980 e, sobretudo de 1990, dando suporte as mais diversas práticas em nosso contexto educacional em ensino de arte. Neste trabalho temos como horizonte discutir parte da trajetória epistemológica da arte-educadora Ana Mae Barbosa para sistematização da Abordagem Triangular, com especial atenção à publicação de seu primeiro livro Teoria e prática da Educação Artística, de 1975, período de transformações no campo de ensino da arte, com a lei 5692/71 e a criação dos cursos de Licenciatura em Educação Artística.
\end{abstract}

PALAVRAS-CHAVE

Abordagem Triangular. Ensino de arte. Formação de professores.

ABSTRACT - Triangular Approach: zigzagging between an ideary and a rebuilding action to art education - The art educator Ana Mae Barbosa organized and published together with Fernanda Pereira da Cunha the book Triangular Approach in the teaching of the arts and visual cultures (CORTEZ, 2010), in which she reviewed the twenty years of experiences with the Triangular Approach in the teaching of arts in Brazil. The book takes a look at some interpretations and reveals facets of this multiple Approach that comes from the 1980s and especially from 1990, supporting the most diverse practices in our educational context in art education. In this work we have as a horizon to discuss part of the epistemological trajectory of art / educator Ana Mae Barbosa to systematize the Triangular Approach, with special attention to the publication of her first book Theory and practice of Art Education, 1975, a period of transformations in the field of teaching of Art, with the law 5692/71 and the creation of Art Education courses.

\section{KEYWORDS}

Triangular Approach. Art Education. Teacher training. 


\section{Os que inventam morros, ou caminhos em movimento ${ }^{1}$...}

Ana Mae Barbosa organizou e publicou junto com Fernanda Pereira da Cunha o livro Abordagem Triangular no ensino das artes e culturas visuais (CORTEZ, 2010), no qual fez um balanço dos vinte anos de experiências com a Abordagem Triangular no ensino de artes no Brasil. O livro faz um apanhado de algumas interpretações e revela facetas dessa múltipla Abordagem que vem desde a década de 1980 e, sobretudo de 1990, dando suporte as mais diversas práticas em nosso contexto educacional em ensino de arte.

Este recente contexto histórico do ensino da arte no Brasil, vem sendo alvo de análises como as de Azevedo (2000, 2016), Bredariolli (2009, 2010, 2013) e Costa (2007), que consideramos como importantes referências no traçado deste desenho. Nos propomos aqui a cooperar com mais uma pedrinha deste mosaico, no nosso caso, buscando compreender a trajetória epistemológica traçada pela professora Ana Mae Barbosa para sistematização da Abordagem Triangular, com especial atenção ao primeiro livro publicado pela arte-educadora, Teoria e prática da Educação Artística (Cultrix, 1975), pois, em nossa leitura percebemos que este livro já revela um processo de deglutição e de apropriação de referências capitais que vão dar esteio à sistematização da Abordagem.

Nessa obra, a autora chama atenção para um ensino de arte em que o professor deve ensinar a ver, assim como levar os alunos a uma reflexão sobre 0 fazer. Estas indicações são sugeridas a partir da análise de práticas pedagógicas desenvolvidas nos Estados Unidos e da experiência da autora frente à Escolinha de Artes de São Paulo², ações que, após serem deglutidas, se farão presentes na triangulação pós-moderna para o ensino de arte sistematizada doze anos após o lançamento desse seu primeiro livro

Frase extraída do texto "Reinvenções de escrituras" de Alessandra Giovanella (2013).

2 Sobre a história e experiências de ensino e aprendizagem de artes na Escolinha de Arte de São Paulo, conferir: LIMA, Sidiney Peterson Ferreira de. Escolinha de Arte de São Paulo: instantes de uma história. 2014. 188 f. Dissertação (mestrado) - Universidade Estadual Paulista Júlio de Mesquita Filho, Instituto de Artes, 2014. Disponível em: <http://hdl.handle.net/11449/110339>. 
Compreendemos que o esforço empreendido naquele momento com a publicação do livro Teoria e prática, se justifica diante da carência de referenciais teóricos para o campo do ensino de arte no Brasil, assim como foi uma reação da autora e pesquisadora diante do que se configurava como um processo de massificação do ideário modernista de ensino de arte, consequência da obrigatoriedade do componente curricular da Educação Artística, através da lei 5692/71 e da criação dos Cursos de Licenciatura em Educação Artística em todo território nacional a partir de 1973.

Assim, voltaremos especialmente até a década de 1970 quando a Educação Artística ganhou espaço e status nos currículos da educação básica. Situando também, o papel do Movimento Escolinhas de Arte (MEA), que naquele momento representado por educadores, psicólogos e artistas teve influência direta na gestão da inclusão da Educação Artística nos currículos. O mesmo Movimento Escolinhas de Arte que também influenciou a formação e atuação de Ana Mae Barbosa, quando ela desenvolveu trabalhos em três Escolinhas ligadas ao Movimento: a Escolinha de Arte do Recife (1956), a Escolinha de Arte de Brasília (1965) e a Escolinha de Arte de São Paulo (1968), além dos cursos e palestras que ministrava como convidada na Escolinha de Arte do Brasil.

\section{A lei 5692/71 e a formação de professores de arte: repercussões do Movimento Escolinhas de Arte (MEA)}

Quando decretada em 11 de agosto de 1971, a lei 5692 que modificava as diretrizes e bases da Educação no Brasil tinha, também, por finalidade adequar o país aos modelos de produção capitalista, ou seja, com o advento do regime militar, imposto desde 1964, "guiado pelo lema segurança e desenvolvimento" (SAVIANI, 2007, p. 365), a adoção de um modelo econômico associado-dependente reforçado com a presença de empresas estrangeiras, estreitou os laços entre o Brasil e os EUA, trazendo para o país o modelo organizacional que as presidia. Assim, a preparação de mão de obra para essas mesmas empresas, associadas à meta de elevação geral da produtividade do sistema escolar levou a adoção daquele modelo organizacional no campo da educação. 
No cenário do ensino de artes daquele momento, o Movimento Escolinhas de Arte exercia grande influência na formação de professores para a área de conhecimento, influência afirmada desde 1958, quando o governo federal brasileiro permitiu a criação de classes experimentais nas escolas públicas e deixou a cargo desse Movimento, composto por educadores oriundos da Escolinha de Arte do Brasil, os cursos de treinamento para os professores de arte.

Em 1961, com a promulgação da Lei de Diretrizes e Bases da Educação, as classes experimentais são extintas. Nesse momento a arte-educadora Noemia Varela e o fundador da Escolinha de Arte do Brasil (EAB) Augusto Rodrigues, com a participação de Nise da Silveira, Helena Antipoff, Cecília Conde, Fayga Ostrower, Ilo Krugli, Léa Elliot, Tom Hudson, Seonaid Robertson, Maria Fux, entre outros educadores, artistas e intelectuais, passaram a difundir os ideais do Movimento Escolinhas de Arte, através de um curso denominado Curso Intensivo de Arte na Educação (CIAE).

Durante a década de 1960, o Curso Intensivo de Arte na Educação, foi o único curso destinado a professores de todos os graus de ensino e que a partir do seu processo criativo e aberto atraiu artistas, estudantes e educadores de arte, tornando possível sua integração em Escolinhas e Escolas (VARELA, 1986, p. 18).

Ao completar dez anos de funcionamento do Curso Intensivo de Arte na Educação, a Escolinha de Arte do Brasil era indiscutivelmente reconhecida enquanto instituição de formação de professores para o ensino de arte, o que levou o Ministério da Educação a organizar em conjunto com representantes da Escolinha de Arte do Brasil, um curso para os responsáveis das Secretarias de Educação que tinha como propósito orientar a implantação da Educação Artística no currículo escolar de acordo com o artigo $7^{\circ}$ da lei 5692/71 (BARBOSA, 1998). Este posicionamento é um dado importante para pensar que a inclusão da Educação Artística no currículo escolar seria o resultado do desejo de professores já envolvidos com o Movimento Escolinhas de Arte de expandir o ideário de educar pela arte na escola formal.

Com o Parecer ํㅜ 1284/73 do Conselho Federal de Educação (CFE), são criados os cursos de Licenciatura em Educação Artística, com dois anos de duração 
(licenciatura curta) e uma nova perspectiva de ensino de arte é estabelecida: a polivalência, consequência de uma interpretação das práticas já divulgadas pelo Movimento Escolinhas de Arte. Assim, as artes plásticas, a música e as artes cênicas (teatro e dança) deveriam fazer parte do currículo da escola básica, portanto, deveriam ser ensinadas pelo professor de Educação Artística, um professor de perfil polivalente.

Envolvida com o Movimento Escolinhas de Arte desde a sua passagem pela Escolinha de Arte do Recife (1956-1964), Escolinha de Arte de Brasília (1965) e na Escolinha de Arte de São Paulo (1968-1971), Ana Mae Barbosa mantinha-se sempre atenta, analisando criticamente as teorias e práticas desenvolvidas a partir da criação do decreto já mencionado, posicionamento crítico exercido com seu mestre Paulo Freire. No livro Teoria e prática da Educação Artística, a autora convoca os arte/educadores a pensar que "nós, professores de Arte, atravessamos um período de justa euforia, provocada pela obrigatoriedade da Educação Artística prevista pelo artigo 7ํㅜ da Lei 5692 [...] e pela concepção humanística que reveste essa norma legal” (BARBOSA, 1975, p. 110). Mas adverte: "dois perigos ameaçam a valoração da Arte como criação na escola [...] considerar a arte apenas como atividade [...] e entender a criação como fator afetivo, que intervém no ato de aprender" (BARBOSA, 1975, p. 111).

Na prática, a Educação Artística foi desenvolvida nas escolas brasileiras de forma incompleta, quando não insipiente, dentro de uma pedagogia conhecida como tecnicista, em que o professor e a professora passam a ser considerados como técnicos responsáveis por um competente planejamento dos cursos escolares. Despreparados e inseguros, os professores de arte passam a se apoiar cada vez mais nos livros didáticos de Educação Artística, que em pesquisa realizada por Maria Heloísa Ferraz e Idméia S. Siqueira (1987), mostra que

A maioria dos professores de Educação Artística entrevistados atua
equivocadamente, pois diz não adotar livros didáticos, mas os utilizam na
preparação de suas aulas (muitas vezes ate copiando o sumário). Além disso,
conhecem poucas obras de fundamentação teórico-metodológica de ensino
e aprendizagem da arte (FERRAZ; SIQUEIRA, 1987, p. 40).

Em um tempo de incertezas, de atuações educacionais limitadas pelas possibilidades de formação da época, Ana Mae Barbosa alertou para a necessidade 
de se buscar "[...] sólidos conhecimentos teóricos acerca das teorias da ArteEducação, e de um modo de pensar acerca da Arte que possa ajuda-los a definir as atividades artísticas na escola e a Arte na sociedade moderna, sua função e praticalidade" (BARBOSA, 1975, p. 94). Tempo de buscar novo pensar e fazer Arte/Educação diferente das ideias que norteavam o ensino de arte operado pela disjunção e redução modernistas da Educação Artística que

\footnotetext{
Chega aos anos 80 sem rumo, completamente isolada e desqualificada dentro das escolas como resultado de seu processo histórico iniciado de forma verticalizada e antidemocrática, bem como, da falta de um arcabouço teórico/metodológico que desse corpo a uma área do conhecimento que passaria a se constituir enquanto disciplina do saber escolar (COSTA, 2005, s/p).
}

Já insatisfeita com tal situação em meados da década de 1970, Ana Mae Barbosa no capítulo IV Arte-Educação: uma experiência programada, que compõe a obra publicada em 1975, chama atenção para suas experiências educacionais na Escolinha de Arte de São Paulo/EASP, evidenciando um pensamento que divergia da busca inalcançável da originalidade e sensibilidade modernistas, ao mencionar como objetivos para o ensino de arte naquela Escolinha, "[...] 0 desenvolvimento da capacidade crítica para analisar a realidade percebida e encorajar o processo criativo, o qual permite novas respostas a esta realidade, até mesmo mudando-a ou transformando-a" (BARBOSA, 1975, p. 70).

A arte-educadora, como afirma Bredariolli (2010, p. 33), insiste na tese de uma alfabetização visual, defendida até sua consumação em proposta, de que "o professor deve ensinar a ver, a analisar, a especular" (BARBOSA, 1975, p. 71), que não por acaso, com base em Paulo Freire, esse ver possibilita "[...] inventividade por exigir a criação da trama textual como expressão histórica e social que muda a face do mundo, desfazendo certezas e instaurando novos modos de perceber o real" (AZEVEDO, 2009, p. 336).

Ainda como pensamento em construção naquele momento, o ver já havia sido trabalhado na Escolinha de Arte de São Paulo (EASP) na forma de leitura de contexto e leitura de imagem, conforme descrição de atividades em subtítulo $A$ teoria posta em prática (BARBOSA, 1975, p. 77) que expõe como objetivo a observação de efeitos gerados por variações contextuais. Nessa atividade analisada no livro, duas lojas de 
design foram visitadas pelos estudantes da EASP, para que eles pudessem perceber a interferência de diferentes contextos sobre um mesmo objeto. Outra atividade relatada, diz respeito à experimentação com recortes e rearranjo de imagens de jornais e revistas, em que o trabalho da estudante Betty Leirner, segundo Ana Mae em análise posterior, proporcionou na Escolinha "as primeiras discussões sobre as diferenças do que hoje chamamos arte-educação modernista e arte-educação pósmoderna" (BARBOSA, 1998, p. 144).

Concordando com Costa (2005), trata-se de uma ação educativa em que a arte faz parte do currículo enquanto área do conhecimento humano, oferecendo aos estudantes um ensino onde conhecer, aprender e compreender sejam essenciais para uma ampla apropriação e experimentação do conhecimento artístico e estético.

\section{O campo aberto para a sistematização da Abordagem Triangular}

Criado em abril de 1963, o Museu de Arte Contemporânea da USP é uma instituição voltada à produção artística nacional e estrangeira, que se destaca por sua ligação ao ensino, à pesquisa e à extensão universitária, constituindo-se como um importante núcleo de pesquisa e formação educacional, pois, na década de 1970, sob a direção de Walter Zanine, instituiu a Arte/educação em um momento em que o trabalho de atelier era predominante no ensino de artes em museus (BARBOSA, 1991).

Em 1987 ocorre uma reestruturação da equipe de arte/educadores do museu e a primeira preocupação da então diretora da instituição, a professora Ana Mae Barbosa, foi dar um claro embasamento teórico através de cursos que foram organizados com os professores John Swift, Annie Smith, David Thistlewood, Robert Ott e Brent Wilson (BARBOSA, 1991), com a ideia de tornar "a equipe flexível a ponto de poder ensinar história da arte através do trabalho de atelier e dar ao fazer artístico, parâmetros históricos privilegiando, em ambos os casos, a leitura da obra de arte." (BARBOSA, 1991, p. 89).

Assim configurava-se a Abordagem Triangular, uma triangulação pós-moderna para o ensino de artes, que inicialmente foi nomeada como Metodologia Triangular, e 
que tinha naquele contexto o objetivo de aprofundar teórica e praticamente o trabalho dos arte/educadores, baseada na leitura da obra de arte, contextualização e fazer artístico, propostos, segundo sua sistematizadora, a partir da deglutição de três outras abordagens epistemológicas, quais sejam, as Escuelas al Aire Libre (México), a Discipline Based Art Education (EUA) e o Critical Studies (Inglaterra).

Com o Critical Studies, Ana Mae Barbosa teve contato em 1982, quando passou um ano em estudos na Inglaterra. Enquanto linha de ensino integradora da ideia de "arte como expressão e como cultura" (BARBOSA, 1998, p. 34), previa a possibilidade de ler, analisar e até reconhecer a obra como um bom exemplo de um estilo ou técnica por estar relacionada à ideia de apreciação, que na abordagem brasileira é ressaltada como leitura crítica em referência as leituras de mundo de Paulo Freire.

Nesse mesmo período, discordando de um ensino modernista que estava embarcando na busca de um estilo universal que transcendia qualquer estilo local, étnico ou popular (EFLAND, 2003), Ana Mae realizava uma pesquisa sobre o Ensino de Arte em três países latino-americanos, quando se entusiasmou com as Escuelas al Aire Libre do México, uma experiência incentivada por José Vasconcelos que buscava ensinar a arte mexicana através da inter-relação entre a Arte e a Expressão na operação ensino/aprendizagem, a exemplo do que fizera Maugard, responsável pela publicação

[...] dos livros didáticos das Escuelas al Aire Libre que tinha como objetivo a recuperação dos padrões de Arte e Artesania mexicana, a constituição de uma gramática visual mexicana, o aprimoramento da produção artística do país, a apreciação da arte local e o incentivo à expressão individual (BARBOSA, 1995, p. 238).

As três ações propostas naquele momento para a Abordagem Triangular, ou seja, a leitura da obra de arte, a contextualização e o fazer artístico, por muito tempo foram confundidas como adaptação do DBAE (Discipline Based Art Education), uma proposta de ensino de arte norte-americana desenhada inicialmente pelo educador Manuel Barkan (1966), que consciente do futuro que aguardava a Educação Artística no contexto filotecnicista, apresentou o documento que deu "origem ao nascimento da corrente de disciplinas em Educação Artística." (ARRIAGA, 2005, p. 232). 
Proposta retomada nos anos 1980 pelos pesquisadores Elliot Eisner, Ralph Smith, Brent Wilson e Marjorie Wilson, que desejavam ampliar a habilidade das crianças em lidar com problemas através de quatro operações constituídas por produção, crítica, história e estética, transformadas em disciplinas. Eis o grande diferencial entre o DBAE e a Abordagem Triangular, já que na proposta brasileira esses componentes são representados por ações e não por disciplinas.

Em seu livro A imagem no ensino da arte, publicado em 1991, Ana Mae Barbosa, expõe seus argumentos para defender uma revisão crítica do ensino da arte, convocando os professores de arte, artistas e intelectuais a:

[...] falar diretamente de ensino da arte e aprendizagem da arte sem eufemismos, ensino que tem de ser conceitualmente revisto na escola fundamental, nas universidades, nas escolas profissionalizantes, nos museus, nos centros culturais e ser previsto nos projetos de politécnicos que se anunciam (BARBOSA, 1991, p. 7).

As ideias sugeridas por Ana Mae Barbosa para ensinar/compreender arte através da leitura de imagens não agradaram muitos professores que, apoiados no modelo de ensino de arte modernista, em que se privilegiava uma certa virgindade visual, a livre expressão e o desenvolvimento da sensibilidade e da criatividade, se depararam com uma proposta que seguia outras vias, quais sejam, a cognição como caminho para compreensão estética e a construção do objeto e sua concepção inteligível, como elementos definidores da arte.

Podemos ponderar que no momento de difusão da Abordagem Triangular, os professores não estavam teoricamente preparados para compreensão das ações propostas nessa triangulação, pois sua formação de base modernista dedicava-se a metodologias pautadas na livre expressão e na criatividade, e um fazer artístico em atelier com pouca fundamentação.

Essas formações foram consolidadas por um ideal de educação através da arte e justificado no decreto de 1971 que determinava o lugar da arte na escola não como disciplina, mas como mera atividade. Este contexto foi questionado por Ana Mae Barbosa em 1975 quando alertava os educadores quanto ao preconceito contra Arte, "pois designa como um campo de exploração emocional, sem atentar para a igual 
participação da inteligência, do pensamento reflexivo na produção artística" (BARBOSA, 1975, p. 111).

\section{Metodologia quem faz é o professor}

Em revisão da Abordagem Triangular, publicada em Tópicos utópicos (1998), a professora Ana Mae Barbosa afirma que metodologia quem faz é o professor em sala de aula, assim propõe que o currículo escolar articule as dimensões da leitura, produção e contextualização, deixando a cargo do professor a construção metodológica de seu ensino. Fica evidente, então, que, o que determinará a "articulação e as possíveis relações entre as três ações é, em parte, o próprio conteúdo selecionado pelo educador e, essencialmente, suas próprias concepções de educação e de arte" (COUTINHO, 2009, p. 173). Daí a variedade de metodologias que se articulam em nome da Abordagem Triangular, algumas fincadas em concepções de arte e de ensino de arte modernista e mesmo anteriores ao modernismo.

No quinto e último capítulo do livro Teoria e prática, visionariamente intitulado Arte-Educação: uma experiência para o futuro, Ana Mae Barbosa já alertava para esta questão. O capítulo comenta o resultado de uma pesquisa sobre planos de ensino dos professores de Arte e de Desenho, no qual se evidencia contradições entre objetivos e métodos. Na análise da autora,

Se, por um lado, a proposição de objetivos parece corresponder a um enfoque atualizado de Arte-Educação, a metodologia utilizada para atingi-los não é nem adequada nem suficiente, isto talvez porque haja uma ausência de reflexão acerca dos próprios objetivos (BARBOSA, 1975, p. 87).

O cuidado com a formação do professor de arte é então apontado como a chave para uma qualificação do ensino de artes, refletir sobre suas concepções e sobre as concepções de artes é o mote do desenvolvimento de todo este capítulo. No subtópico Função da arte na educação e na sociedade, temos o alerta sobre a necessidade de um entendimento da teleologia da arte por parte do professor (1975, p.90). E o livro termina com indicações e sugestões para cursos de atualização para professores, organização de curso de licenciatura, orientações para secretarias de educação. Não é por acaso que esta obra tem aparecido com frequência em bibliografias de editais 
de concursos municipais e estaduais em todo território nacional e também como base teórica na elaboração de documentos como o Parecer 540/1977.

O livro é registro de uma reflexão crítica sobre uma época e um contexto específico. O livro traz a tona os rudimentos do que se configurará como Abordagem Triangular treze anos depois de sua publicação. O livro é testemunho do início de uma jornada em prol da qualificação do ensino de artes no Brasil. É, portanto, um livro que pode ser lido como um documento, como parte de uma história, mas é também um livro que tem uma potência atemporal, pois fala de uma importante articulação da arte como processo e como produto no contexto da Educação. O livro termina com estas sugestões:

\begin{abstract}
A Arte não tem importância para o homem somente como instrumento para desenvolver sua criatividade, sua percepção, etc., mas tem importância em si mesma, como assunto, como objeto de estudos.

Além disso, nem toda criança virá a ser um produtor de Arte, mas todas poderão ser observadores efetivos, extraindo do consumo visual os mesmos benefícios auferidos na ação sobre os materiais e na construção de símbolos. Para isso é necessário que aprendam, pela contemplação, que o objeto de arte age sobre quem o observa, organizando sentimentos e ideias e permitindo que o processo de interpretar imagens mobilize o potencial criativo, da mesma maneira que o processo de produzi-las.

$[\ldots]$

$\mathrm{Na}$ Educação, os modos de ver a Arte de dentro e de ver a Arte de fora se completam. Devemos, portanto, educar os estudantes em Arte e através da Arte (BARBOSA, 1975, p. 113).
\end{abstract}

\title{
Referências
}

ARRIAGA, Imanol Aguirre. Teorías y prácticas en educación artística. Barcelona: Octaedro/EUBUniversidade Pública de Navarra, 2005.

AZEVEDO, Fernando Antônio G. Movimento Escolinhas de Arte: em cena D. Noemia Varela e Ana Mae Barbosa. Dissertação (Mestrado) Escola de Comunicações e Arte, Universidade de São Paulo, São Paulo, 2000.

AZEVEDO, Fernando Antônio G. A arte possibilita ao ser humano repensar suas certezas e reinventar seu cotidiano, In BARBOSA, Ana Mae; COUTINHO, Rejane Galvão (Org.). Arte/Educação como mediação cultural e social. São Paulo: UNESP, 2009, p. 336.

BARBOSA, Ana Mae. Teoria e prática da Educação Artística. São Paulo: Cultrix, 1975.

BARBOSA, Ana Mae. Tópicos utópicos. Belo Horizonte: C/Arte, 1998.

BARBOSA, Ana Mae. A imagem no ensino da arte: anos oitenta e novos tempos. 1 ed. São Paulo: Perspectiva, 1991.

BARBOSA, Ana Mae. Abordagem Triangular não é receita pronta. In: ARTE NA ESCOLA. Anais do Primeiro Seminário Nacional Sobre o Papel da Arte no Processo de Socialização e Educação da Criança e do Jovem. São Paulo: UNICSUL, 1995. 
BARBOSA, Ana Mae; CUNHA, Fernanda P. da (Org.). A Abordagem Triangular no ensino das artes e culturas visuais. São Paulo: Cortez, 2010.

BREDARIOLLI, Rita Luciana B. XIV Festival de Inverno de Campos do Jordão: variações sobre temas de Ensino da Arte. Tese (Doutorado) Escola de Comunicações e Artes, Universidade de São Paulo, São Paulo, 2009.

BREDARIOLLI, Rita Luciana B. Choque e formação, In: BARBOSA, Ana Mae; CUNHA, Fernanda P. da (Org.). A Abordagem Triangular no ensino das artes e culturas visuais. São Paulo: Cortez, 2010.

BREDARIOLLI, Rita Luciana B. Ao revés do pós: variações sobre temas de arte e educação. São Paulo: UNESP, 2013.

COSTA, Fábio José Rodrigues da. Didáticas das artes visuais: uma proposição pós-moderna. Tese (Doutorado) Universidade de Sevilla, Sevilla, Espanha, 2007.

COSTA, Fábio José Rodrigues da. Ensino da arte e Proposta Triangular: do pós-moderno ao pósmodernismo. Revista Digital Art\&, no 4, outubro de 2005.

COUTINHO, Rejane Galvão. O que fazer com a cultura visual da escola? Revista VIS: Programa de Pós-Graduação em Arte da UnB, Brasília, v. 8, n 1, p. 60-67, jan./jun. 2009.

COUTINHO, Rejane Galvão. Estratégias de mediação e a Abordagem Triangular. In: BARBOSA, Ana Mae; COUTINHO, Rejane Galvão (Org.). Arte/Educação como mediação cultural e social. São Paulo: UNESP, 2009.

GIOVANELLA, Alessandra. Reinvenções de escrituras. In: ZÓZIMO, Michel (Org.). Assim que for editado Ihe envio. Porto Alegre: Modelo de Nuvem, 2013.

EFLAND, Arthur D. La educación en el arte posmoderno. Barcelona: Paidós, 2003.

FERRAZ, Maria Heloísa C. de T.; FUSARI, Maria F. de Rezende e. Arte na prática pedagógica. 4 ed. São Paulo: Cortez, 2010.

FERRAZ, Maria Heloísa C. de T.; SIQUEIRA, Idméa S. P. Arte-Educação: vivência, experienciação ou livro didático? 2ª ed. São Paulo, 1987.

FREIRE, Paulo. Pedagogia da autonomia: saberes necessários à prática educativa. 43 ed. São Paulo: Paz e Terra, 2011.

SAVIANI, Demerval. História das ideias pedagógicas no Brasil. Campinas: Autores Associados, 2007.

VARELA, Noemia. A formação do arte-educador no Brasil. In: BARBOSA, Ana Mae. História da Arteeducação: a experiência de Brasília. São Paulo: Max limonad, 1986.

\section{Sidiney Peterson}

Doutorando do Programa de Pós-Graduação em Artes do Instituto de Artes da UNESP - Universidade Estadual Paulista Júlio de Mesquita - na Área de Concentração de Arte e Educação; Linha de Pesquisa de Processos Artísticos, Experiências Educacionais e Mediação Cultural (ingresso em 2016)- Bolsista FAPESP; Mestre em Artes pelo Instituto de Artes da UNESP - na Linha de Ensino de Aprendizagem da Arte -, em 2014; graduado em Pedagogia pela Unidade Acadêmica de Garanhuns (UAG)/ Universidade Federal Rural de Pernambuco (UFRPE), em 2010. Tem experiência na área de Educação, com ênfase em Educação em Museus e Mediação Cultural, atua como coordenador e supervisor de setores educativos em exposições de artes. Tem desenvolvido pesquisas com foco na história do ensino de Artes e formação de professores.

E-mail: sidney.peterson@gmail.com

Currículo: http://lattes.cnpq.br/7897838185394600 


\section{Rejane Coutinho}

Graduada em Educação Artística pela Universidade Federal de Pernambuco (1988), mestrado (1998) e doutorado (2002) em Artes pela Universidade de São Paulo, Pós-doutorado pela Universidade Pública de Navarra, Espanha (2011/2012). É professora do Instituto de Artes da Universidade Estadual Paulista (UNESP), onde atua na Licenciatura em Artes Visuais e na Pós-Graduação em Artes, área de Arte e Educação. Coordenadora do Mestrado Profissional em Artes, Prof-Artes, do Instituto de Artes da UNESP. Tem desenvolvido pesquisas com foco na história do ensino de artes e na formação de arte/educadores e mediadores culturais.

E-mail: rejanegcoutinho@gmail.com

Currículo: http://lattes.cnpq.br/9150659098334633

Recebido em 1 de março de 2017 Aceito em 27 de junho de 2017 